\title{
Is the Inversion in the Trend of the Lethality of the COVID-19 in the Two Hemispheres due to the Difference
} in Seasons and Weather?

\author{
Mauro Giovanni Carta ${ }^{1(D)}$, Goce Kalcev ${ }^{2 *}{ }^{(i)}$, Alessandra Scano ${ }^{3}$ (i) , Ferdinando Romano $^{4}$ (iD), Giulia \\ Cossu $^{1(i)}$, Roberto Littera ${ }^{8(i)}$, Andrea Perra ${ }^{8(i)}$, Simona Deidda ${ }^{5}$ id , Davide Firinu ${ }^{6}$, Stefano Del \\ Giacco $^{6(i)}$, Marcello Campagna ${ }^{7}$ (i), Luchino Chessa ${ }^{8}$ (D), Luigi Zorcolo ${ }^{5}$ (i), Angelo Restivo ${ }^{5}$ (i), \\ Germano Orrù 3 (iD
}

1 Department of Medical Sciences and Public Health, University of Cagliari, Italy; mgcarta@tiscali.it (M.G.K.); giuliaci@icloud.com (G.C.);

2 International PhD in Innovation Sciences and Technologies, University of Cagliari, Italy; gocekalcev@ yahoo.com (G.K.);

3 Department of Surgical Sciences, University of Cagliari, Italy; alessandrascano@libero.it (A.S.); gerorru@gmail.com (G.O.);

4 University La Sapienza, Rome, Italy; ferdinando.romano@uniroma1.it (F.R.);

5 Colorectal Surgery Unit, Department of Surgical Science, University of Cagliari, Italy; simonadeidda86@gmail.com (S.D.); zorcolo@medica.unica.it (L.Z.); arestivo@unica.it (A.R.);

6 Internal Medicine, Allergy and Clinical Immunology, Department of Medical Sciences, University of Cagliari, Italy; davide.firinu@unica.it (D.F.); delgiac@gmail.com (S.D.G.);

7 Occupational Health Section, Department of Medical Sciences and Public Health, University of Cagliari, Italy; mcampagna@unica.it (M.C.);

8 Center for the Study of Liver Diseases, Department of Medical Sciences, University of Cagliari, Italy; roby.litter@gmail.com (R.L.); andreaperra@omeca.it (A.P.); luchinochessa@ unica.it (L.C.);

* Correspondence: gocekalcev@yahoo.com;

Received: 1.10.2020; Revised: 21.10.2020; Accepted: 23.10.2020; Published: 26.10.2020

Abstract: The climate has an influence on the COVID-19 virus lethality. The aim of this study is to verify if the summer weather coincided with the decrease of the Case Fatality Ratio (CFR) in Europe and if, on the contrary, an inverse trend was observed in Australia and New Zealand. To verify our hypothesis, we considered the largest European countries (Germany, UK, France, Italy, and Spain), plus Belgium and the Netherlands. Furthermore, we compared these countries with Australia and New Zealand. For each country considered, we have calculated the CFR from the beginning of the pandemic to May 6th and from May 6th to September 21st (late summer in Europe, late winter in the southern hemisphere). The CFRs were calculated from the John Hopkins University database. According to the results, in all European countries, a progressive decrease in CFR is observed. A diametrically opposite result is found in Australia where, on the contrary, the CFR is much higher at the end of September (at the end of winter) than on May 6th (mid-autumn), and the risk of dying if we count the infection is higher in September. In New Zealand, there are no statistically significant differences between the two surveys. The present study was based on public access macro data.

Keywords: COVID-19; climate; hemispheres; season; lethality.

(C) 2020 by the authors. This article is an open-access article distributed under the terms and conditions of the Creative Commons Attribution (CC BY) license (https://creativecommons.org/licenses/by/4.0/).

\section{Introduction}

The lethality of the COVID-19 virus is affected by climate [1]. The Case Fatality Ratio (CFR) of COVID-19 is, in fact, lower in equatorial countries than in temperate climates [2]. This phenomenon is partially independent of the different age distribution of the populations, and it also regardless of previous exposure to the malaria of the given areas; malaria [3] and 
old age $[4,5]$ are in fact debated as possible determinants of lethality in the COVID-19 pandemic, the first as a possible protective, and the second as a risk factor. A low lethality is also detectable in urban equatorials countries with high pollution rates (e.g., Singapore) [6] while the association is less strong in equatorials countries with a high proportion of the population living in altitude, and therefore with milder temperatures, such as in Ecuador [7]. In Europe, a relationship emerged between temperature, humidity, and incidence and mortality from COVID [8]. While in more detail, another study found European countries with a temperate climate with higher CFR both than European countries with a warmer Mediterranean climate, as towards European countries with a cold climate [9]. The spread of the virus could also be affected by the climate; however, the evidence is less convincing in this regard [10]. A summary analysis of trends in Europe seems to highlight that in many European countries. The so-called second wave is showing a lower CFR than the first 7].

If this were confirmed, we could hypothesize several determinants of this trend:

1) First of all, the therapeutic systems were improved, and this could lead to a lowering of the risk of death.

2) The awareness of the importance of asymptomatic and paucisymptomatic carriers has raised the number of diagnostic tests. This was accompanied by an improvement in the screening test and the accessibility of it. With the result that the denominator is increased because it is much more likely that people had no contact with the virus will be tested.

3) The first phase of the epidemic in Europe saw as focal points hospitals (often unprepared) and nursing homes for the elderly (with the involvement of elderly people more at risk of a fatal outcome), while the second wave in many countries exploded in summer party nights and in schools (with the involvement of young people, less at risk of a bad outcome).

4) The virus may have lost its virulence due to natural evolution, perhaps in relation to modulating factors such as preventive measures such as masks [11].

Although, if a reverse trend relative to the CFR may be shown in countries of the other hemisphere where the epidemic then exploded at the end of the summer and continued in the autumn and then in the winter (while in Europe it was summer), this could suggest that the climate may have played an important role. However, we should consider nations that had the majority of the population living in temperate climates, with a healthy structure similar to that of European countries (i.e., with public national health systems) with similar income and with similar cultural and social roots. The countries closest to this description are Australia and New Zealand. The purpose of this study is to verify if the summer weather coincided with the decrease of the CFR in Europe and if, on the contrary, an inverse trend was observed in Australia and New Zealand.

\section{Materials and Methods}

To verify our hypothesis, we considered the largest European countries by the number of inhabitants (Germany, UK, France, Italy, and Spain), plus Belgium and the Netherlands, because they are particularly affected by the pandemic. We have reported the data relating to Sweden, which, although located for most of its territory in a colder climatic zone than the rest of the European countries considered, has the interest determined by the fact that it is the only European country not to have operated a look down. We compared these countries with Australia and New Zealand. For each country considered, we have calculated the CFR from the beginning of the pandemic to May $6^{\text {th }}$ and from May $6^{\text {th }}$ to September $21^{\text {st }}$ (late summer in Europe, late winter in the southern hemisphere). The CFRs were calculated from the John 
Hopkins University database [7]. The difference between the two detection times in each group was calculated on the basis of 2X2 tables that reported in the 4 cells: cases that died at time 1 , cases that did not die at time1, cases that died at time 2, cases that did not die at time2. The differences are reported as odds ratio (OR), risk of death at $\mathrm{t} 1$ compared to $\mathrm{t} 2$, the confidence limits were calculated with the simplified formula of Miettinen starting from the calculation of the chi-square. To ascertain at what moment of evolution of the epidemic in the specific state of the two surveys, we also calculated what percentage of cases had been highlighted on May $6^{\text {th }}$, compared to all cases highlighted on September $21^{\text {st }}$.

\section{Results and Discussion}

Table 1 shows how in all European countries, a progressive decrease in CFR is observed, more marked in France, Belgium, The Netherlands, Spain (OR from 6.6 to 40), less marked in Italy, Germany, and UK (OR=2.1-2.9), intermediate in Sweden (OR=4.1). However, in all these countries, the differences between the first and second surveys are statistically significant, with a higher CFR on the first survey (in the middle of spring) than on the second one (in late summer). A diametrically opposite result is found in Australia where, on the contrary, the CFR is much higher at the end of September (at the end of winter) than on May $6^{\text {th }}$ (mid-autumn), and the risk of dying if we count the infection is higher in September. In New Zealand, there are no statistically significant differences between the two surveys. At the time of the first survey, $81 \%$ of total cases had already been detected up to September $21^{\text {st }}$ in New Zealand, $71 \%$ in Italy, and 60\% in Germany. In all other states, half of the total cases that would have been detected at the end of the research had not yet been detected on May $6^{\text {th }}$, with lower percentages in Australia (25\%), Sweden (27\%), and France (33\%).

Table 1. CFR in Europe, Australia, and New Zealand from the outbreak of the pandemic to May $6^{\text {th }}$ and from May $6^{\text {th }}$ to September $21^{\text {st }}$.

\begin{tabular}{l|c|c|c|c|c|c} 
& $\begin{array}{c}\text { CFR } \\
\text { To May 6 }^{\text {th }}\end{array}$ & $\begin{array}{c}\text { CFR May 6 } \\
\text { September 2 }^{\text {st }}\end{array}$ & $\begin{array}{c}\text { Chi } \\
\text { square }\end{array}$ & p & OR (CI 95\%) & $\begin{array}{c}\text { \% of total cases at } \\
\text { the first evaluation }\end{array}$ \\
\hline Italy & $13.8 \%$ & $6.9 \%$ & 2844.6 & $<0.00001$ & $2.1(2.0-2.2)$ & $71.0 \%$ \\
\hline France & $14.8 \%$ & $1.6 \%$ & 35409.2 & $<0.00001$ & $10.1(10.4-10.7)$ & $33.5 \%$ \\
\hline Belgium & $16.4 \%$ & $2.9 \%$ & 5778.7 & $<0.00001$ & $6.6(6.2-7.0)$ & $47.5 \%$ \\
\hline Germany & $4.3 \%$ & $1.9 \%$ & 1154.6 & $<0.00001$ & $2.3(2.2-2.4)$ & $60.2 \%$ \\
\hline The Netherlands & $11.0 \%$ & $1.9 \%$ & 21646.3 & $<0.00001$ & $40(37-43)$ & $44.1 \%$ \\
\hline Spain & $11.7 \%$ & $1.1 \%$ & 40644.9 & $<0.00001$ & $12.1(11.7-12.5)$ & $31.2 \%$ \\
\hline UK & $14.9 \%$ & $5.7 \%$ & 9634.9 & $<0.00001$ & $2.9(2.8-3.0)$ & $48.7 \%$ \\
\hline Sweden & $13.9 \%$ & $3.7 \%$ & 3014.0 & $<0.00001$ & $4.1(3.9-4.3)$ & $27.2 \%$ \\
\hline Australia & $1.4 \%$ & $3.8 \%$ & 95.4 & $<0.00001$ & $0.4(0.3-0.5)$ & $25.5 \%$ \\
\hline New Zealand & $1.4 \%$ & $1.2 \%$ & $0.05^{*}$ & 0.995 & $1.2(3.4-3.5)$ & $81.5 \%$
\end{tabular}

*Yates corrected

\subsection{Discussion.}

Our study highlighted a lowering of the CFR in all European countries from May to the end of September, while in the southern hemisphere, an exact opposite trend is observed in Australia, while in New Zealand, there is no difference between the two surveys. Although the results confirm, at least in part, the initial hypothesis, it can nevertheless be affirmed that the same data also suggest, which was also intuitive, that numerous other factors come into play on the trend of the CFR. The same trend of the pandemic seems to be able to influence the parameter considered, where, in all the countries in which it had a lower prevalence after the first survey, both in the southern and northern hemispheres, the CFR has changed less. In fact, in Europe, there is a minor change (although still present) in Italy (where after May $6^{\text {th }}$, 
positives equal to only $30 \%$ of the total will be identified) and in Germany (40\% of the total). While in the southern hemisphere, the CRF does not change at all in New Zealand, where 80\% of the cases have already been identified as of May $6^{\text {th }}$ and will then be identified until September $21^{\text {st }}$. It is possible that in countries with a better containment of the pandemic, its evolution, relegated to outbreaks, may mainly affect clusters of vulnerable people while where pandemic affects the entire population without control, a greater proportion of people, not at risk, are more likely to become infected. The spreading capacity of the virus presents in the South as in the North and at different times, a similar variability. Suffice it to say that the two southern nations are at the extremes of the distribution of the difference in the percentage of cases identified in the two surveys. Australia will, in fact, develop a consistent epidemic after May $6^{\text {th }}$ (only $25.5 \%$ of the cases identified before), while New Zealand will succeed to almost totally block the spread. This suggests that the diffusivity of the virus is less affected than the lethality by climatic conditions, and those variables such as the effectiveness of preventive measures have greater importance on the ability of the virus to spread [12]. It is no coincidence that in Europe, the country with the highest percentage diffusion after May $6^{\text {th }}$ in Sweden, the only country not to have instituted a lockdown. At the present time, we do not know why a virus that appears capable of spreading in summer and winter proves less lethal when the climate is not temperate. The phenomenon could depend on the greater incidence in winter in temperate climates of concomitant infections that can facilitate manifestations associated with an unfortunate outcome [13] or by the temperature can directly influence the penetration of the virus in particular sites, and the link with particular receptors (but not with all) [14], or could depend on the role of Vitamin D in relationship with the sun [15, 25]. It has also been hypothesized that the widespread use of prevention devices could have attenuated the virus regardless of the climate [16]. Many observations have reported that in Europe in the new phase, forms with a benign course are also observed in the elderly despite very high viral loads. Understanding these phenomena could be interesting to better manage the present epidemic but also to better understand the ecology of the Coronavirus, considering that the two previous epidemics also subsided in the summer. However, the evidence that the COVID-19 pandemic may present a worsening of the CFR as occurred in Australia and that this worsening is related to the cold season should alarm European public health experts in view of the arrival of next winter $[17,18]$. The concern would be even greater if we consider that the European population is on average significantly older than that of Australia and New Zealand [19] and, consequently, conditions of disability such as oncologic [20,21], diabetes [22], cardiovascular [23] and respiratory diseases [24] are also more frequent, and that could make the impact of the winter wave really devastating in such countries.

\section{Conclusions}

The present study was based on public access macro data and, therefore, could not consider relevant variables such as the age of infected people, environmental pollution and could not consider specific biological parameters. Its value is, therefore, purely heuristic. Moreover, the authors consider that this work can be used as a beginning of a new direction in future research investigating the intensity of the link between the climate and the severity of COVID-19. 


\section{Funding}

This research received no external funding.

\section{Acknowledgments}

Goce Kalcev (M.D.) was participating in the writing of this paper in the framework of the International Ph.D. in Innovation Sciences and Technologies at the University of Cagliari, Italy.

\section{Conflicts of Interest}

The authors declare no conflict of interest.

\section{References}

1. Carta, M.; Scano, A.; Lindert, J.; Bonanno, S.; Rinaldi, L.; Fais, S.; Orrù, G. Association between the spread of COVID-19 and weather-climatic parameters. European review for medical and pharmacological sciences 2020, 24, 8226-8231, https://doi.org/10.26355/eurrev_202008_22512.

2. Carta, M.G.; Orrù, G.; Scano, A.; Coghe, F.; Nunnari, G.; Facchini, G.; Numis, F.G.; Berretta, M. In the face of the SARS-CoV-2 outbreak, do people suffering from oncological disease need specific attention? Eur Rev Med Pharmacol Sci 2020, 24, 3434-3436, https://doi.org/10.26355/eurrev_202004_20794.

3. Napoli, P.E.; Nioi, M. Global Spread of Coronavirus Disease 2019 and Malaria: An Epidemiological Paradox in the Early Stage of A Pandemic. Journal of Clinical Medicine 2020, 9, https://doi.org/10.3390/jcm9041138.

4. Naaraayan, A.; Nimkar, A.; Hasan, A.; Pant, S.; Durdevic, M.; Elenius, H.; Nava Suarez, C.; Jesmajian, S. Analysis of Male Sex as a Risk Factor in Older Adults With Coronavirus Disease 2019: A Retrospective Cohort Study From the New York City Metropolitan Region. Cureus 2020, 12, e9912-e9912, https://doi.org/10.7759/cureus.9912.

5. Carta, M.G.; Romano, F.; Orrù, G.The True Challenges of the Covid-19 Epidemics: The Need for Essential Levels of Care for All. Open Respir Med J 2020, 14, 8-9, https://doi.org/10.2174/1874306402014010008.

6. Peters, I.M.; Brabec, C.; Buonassisi, T.; Hauch, J.; Nobre, A.M. The Impact of COVID-19-Related Measures on the Solar Resource in Areas with High Levels of Air Pollution. Joule 2020, 4, 1681-1687, https://doi.org/10.1016/j.joule.2020.06.009.

7. John Hopkins University, Coronavirus Resource Center 2020. Available at: https://coronavirus.jhu.edu/ retrieved, 2020.

8. Meo, S.; Abukhalaf, A.; Alomar, A.; Sumaya, O.; Sami, W.; Shafi, K.; Meo, A.; Usmani, A.; Akram, J.J.E.r.f.m.; sciences, p. Effect of heat and humidity on the incidence and mortality due to COVID-19 pandemic in European countries. 2020, 24, 9216-9225, https://doi.org/10.26355/eurrev_202009_22874.

9. Orrù, G, Romano, F.; Scano, A.; Restivo, A.; Del Giacco, S.; Deidda, S.; Firinu, D.; Campagna, M.; Cossu, G.; Kalcev, G.; Carta, M.G. Climate in the European Union and the enlarged European regionis a determinant of COVID-19 Case Fatality Ratio. In press 2020.

10. Prata, D.N.; Rodrigues, W.; Bermejo, P.H. Temperature significantly changes COVID-19 transmission in (sub)tropical cities of Brazil. Science of The Total Environment 2020, 729, https://doi.org/10.1016/j.scitotenv.2020.138862.

11. Seligmann, H.; Iggui, S.; Rachdi, M.; Vuillerme, N.; Demongeot, J. Inverted Covariate Effects for First versus Mutated Second Wave Covid-19: High Temperature Spread Biased for Young. Biology 2020, 9 , https://doi.org/10.3390/biology9080226.

12. Kubota, Y.; Shiono, T.; Kusumoto, B.; Fujinuma, J. Multiple drivers of the COVID-19 spread: The roles of climate, international mobility, and region-specific conditions. PLOS ONE 2020, 15, https://doi.org/10.1371/journal.pone.0239385.

13. Harrison, S.L.; Fazio-Eynullayeva, E.; Lane, D.A.; Underhill, P.; Lip, G.Y.H. Comorbidities associated with mortality in 31,461 adults with COVID-19 in the United States: A federated electronic medical record analysis. PLOS Medicine 2020, 17, https://doi.org/10.1371/journal.pmed.1003321.

14. Huang, J.; Chen, S.; Lu, X.; Zhao, Q.; Rao, D.C.; Jaquish, C.E.; Hixson, J.E.; Chen, J.; Wang, L.; Cao, J.; Li, J.; Li, H.; He, J.; Liu, D.-P.; Gu, D. Polymorphisms of ACE2 are Associated with Blood Pressure Response to Cold Pressor Test: The GenSalt Study. American Journal of Hypertension 2012, 25, 937-942, https://doi.org/10.1038/ajh.2012.61.

15. Maghbooli, Z.; Sahraian, M.A.; Ebrahimi, M.; Pazoki, M.; Kafan, S.; Tabriz, H.M.; Hadadi, A.; Montazeri, M.; Nasiri, M.; Shirvani, A.; Holick, M.F. Vitamin D sufficiency, a serum 25-hydroxyvitamin D at least 30 
$\mathrm{ng} / \mathrm{mL}$ reduced risk for adverse clinical outcomes in patients with COVID-19 infection. PLOS ONE 2020, 15, https://doi.org/10.1371/journal.pone.0239799.

16. O’Dowd, K.; Nair, K.M.; Forouzandeh, P.; Mathew, S.; Grant, J.; Moran, R.; Bartlett, J.; Bird, J.; Pillai, S.C. Face Masks and Respirators in the Fight Against the COVID-19 Pandemic: A Review of Current Materials, Advances and Future Perspectives. Materials 2020, 13, https://doi.org/10.3390/ma13153363.

17. Petretto, D.R.; Masala, I.; Masala, C.J.C.p.; CP, e.i.m.h.; EMH. School Closure and Children in the Outbreak of COVID-19. Clinical Practice \& Epidemiology in Mental Health 2020, 16, 189-191.

18. Cacciapaglia, G.; Cot, C.; Sannino, F. Second wave COVID-19 pandemics in Europe: a temporal playbook. Scientific Reports 2020, 10, https://doi.org/10.1038/s41598-020-72611-5.

19. Sancassiani, F.; Romano, F.; Preti, A. The Relevance of the Research on the Psychosocial Dimensions of Aging Is Really the Same in Europe and USA? Clin Pract Epidemiol Ment Health 2019, 15, 8-9, https://doi.org/10.2174/1745017901915010008.

20. La Nasa, G.; Caocci, G.; Morelli, E.; Massa, E.; Farci, A.; Deiana, L.; Pintus, E.; Scartozzi, M.; Sancassiani, F. Health Related Quality of Life in Patients with Onco-hematological Diseases. Clin Pract Epidemiol Ment Health 2020, 16, 174-179, https://doi.org/10.2174/1745017902016010174.

21. Cossu, G.; Saba, L.; Minerba, L.; Mascalchi, M. Colorectal Cancer Screening: The Role of Psychological, Social and Background Factors in Decision-making Process. Clin Pract Epidemiol Ment Health 2018, 14, 63-69, https://doi.org/10.2174/1745017901814010063.

22. Maddaloni, E.; D'Onofrio, L.; Alessandri, F.; Mignogna, C.; Leto, G.; Coraggio, L.; Sterpetti, S.; Pascarella, G.; Mezzaroma, I.; Lichtner, M.; Pozzilli, P.; Eugenio Agrò, F.; Rocco, M.; Pugliese, F.; Maria Mastroianni, C.; Buzzetti, R. Clinical features of patients with type 2 diabetes with and without Covid-19: a case control study (CoViDiab I). Diabetes Research and Clinical Practice 2020, 21, https://doi.org/10.1016/j.diabres.2020.108454.

23. Liu, J.; Virani, S.S.; Alam, M.; Denktas, A.E.; Hamzeh, I.; Khalid, U. Coronavirus disease-19 and cardiovascular disease: A risk factor or a risk marker? Reviews in Medical Virology 2020, 2172, https://doi.org/10.1002/rmv.2172.

24. Yao, Y.; Wang, H.; Liu, Z. Expression of ACE2 in airways: implication for COVID-19 risk and disease management in patients with chronic inflammatory respiratory diseases, Clin Exp Allergy 2020, https://doi.org/10.1111/cea.13746.

25. Kalcev, G.; Preti, A.; Orrù, G.; Carta, M.G. Mental Health and the COVID-19 Pandemic: A Call for Action. The Open Public Health Journal 2020, 13, 411-412, https://doi.org/10.2174/1874944502013010411. 